\title{
Hemodynamic Changes in Portal Vein and Frequencies of Acute and Chronic Portal Vein Thrombosis in Pediatric Patients Presenting with Hematemesis
}

\author{
Ahmad Imran, ${ }^{1}$ Amna Tariq, ${ }^{2}$ Abid Ali Qureshi ${ }^{3}$
}

\begin{abstract}
Objective: The objective of the study is to calculate the frequency of portal vein thrombosis in pediatric patients presenting with hematemesis and to estimate the frequency of acute and chronic portal vein thrombosis in these cases.

Patients and Methods: Pediatric patients of $1-15$ years of age of either sex, presenting to emergency or gastroenterology department with complaint of hematemesis were included. Informed consent was taken from parents/guardians. This is a Descriptive cross sectional study conducted in department of pediatric radiology, Children Hospital and Institute of child Health Lahore from 11-12-2012 to 10-6-2013. Doppler ultrasound of these patients was performed at Core Vision pro SSA 350-A Doppler machine (Toshiba,
\end{abstract}

\footnotetext{
${ }^{1}$ Medical Officer

Department of Radiology, Children Hospital and Institute of Child Health, Lahore

${ }^{2}$ PGR, Department of Radiology, Children Hospital and Institute of Child Health, Lahore

${ }^{3}$ Associate Professor/Head of Radiology

Children Hospital and Institute of Child Health, Lahore
}

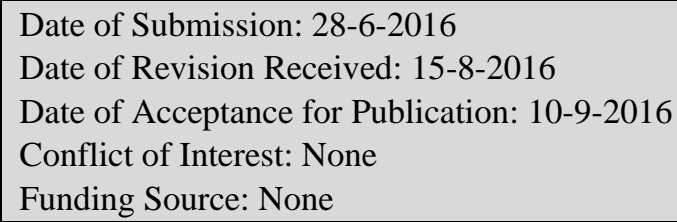

\section{Contribution}

All Authors have contributed in Study Design, Data Collection, Data Analysis, Data Interpretation, Manuscript Writing and Approval.
Japan) using standard imaging protocols. The data was analyzed using SPSS version 17.0 (SPSS Inc., IL, Chicago, USA)

Results: In this study, $41 \%(\mathrm{n}=41)$ between $1-5$ years, $38 \%(\mathrm{n}=38)$ between $6-10$ years and only $21 \%(\mathrm{n}=21)$ between $11-15$ years of age, $64 \%(\mathrm{n}=$ $64)$ were male and remaining $36 \%(n=36)$ were females, frequency of portal vein thrombosis in pediatric patients presenting with hematemesis reveals in $37 \%$ $(n=37)$ while $63 \%(n=63)$ had no findings of PVT, frequency of acute and chronic forms in patients positive for portal vein thrombosis was $40.54 \%(n=15)$ had acute and 59.46\% $(\mathrm{n}=22)$ had chronic portal vein thrombosis.

Conclusion: We concluded that the frequency of portal vein thrombosis in pediatric patients presenting with hematemesis and frequency of acute and chronic forms in patients positive for portal vein thrombosis is in accordance with other studies while color Doppler ultrasound is a useful diagnostic modality being noninvasive and cost effective.

Key Words: Hematemesis, Portal vein thrombosis, Color Doppler Ultrasound.

\section{Introduction}

Portal vein thrombosis (PVT) refers to the complete or partial obstruction of blood flow in the portal vein, due to the presence of a thrombus in the vessel lumen. ${ }^{1}$ The first case of PVT was reported in 1868 by Balfour and Stewart, describing a patient presenting splenomegaly, ascites, and variceal dilation. ${ }^{2}$ Portal vein thrombosis is one of the most common cause for pre-hepatic portal hypertension. ${ }^{3}$ Portal vein thrombosis not only presents as a common complication of liver cirrhosis, 
but it is also seen in the absence of overt liver diseases. $^{4}$

Systemic and local risk factors are responsible for development of portal vein thrombosis. ${ }^{5}$ It is difficult to obtain accurate epidemiological data on portal vein thrombosis, however in U.S.A prevalence in an autopsy research is $0.05 \%-0.5 \%{ }^{6}$. It is reported that in general population life time risk of getting PVT is $1 \%{ }^{7}$ The reported incidence of portal vein thrombosis in children presenting with upper G.I bleed caused by esophageal varices is $40 \% .^{8}$ However the incidence may be as high as $30 \%$ in patients with hepatocellular carcinoma. ${ }^{10}$ Portal vein thrombosis accounts for $5-$ $10 \%$ of all cases of portal hypertension. ${ }^{7}$

Causes of portal vein thrombosis are multifactorial and the diagnosis of portal vein thrombosis is made by color Doppler ultrasound as it is noninvasive with sensitivity of $96 \%$ to $100 \%$, specificity of $90 \%$ to $96 \%$ and a negative predictive value of $98 \% .^{9,11}$ Its diagnostic accuracy is based upon its ability to detect hemodynamic information along with location of blood vessel, direction and rate of flow. ${ }^{12}$

Bleeding episodes have a remarkable impact on the quality of life of affected patients. Thus prompt diagnosis and treatment are needed in order to reduce morbidity and mortality.

The management of acute and chronic forms of portal vein thrombosis also differs. In chronic stage cavernous transformation at porta hepatitis is an important indicator, by which two forms can be differentiated.

No study or data is available regarding hemodynamic changes in acute and chronic forms of portal vein thrombosis and their frequencies particularly among pediatric patients. This study will act as a baseline study in future for further evaluation and research on this topic, and it will also help the radiologists in establishing accurate non-invasive diagnosis of acute and chronic portal vein thrombosis among pediatric patients by determining various hemodynamic changes in portal vein. $^{13}$

\section{Patients and Methods}

Color Doppler ultrasound of 100 Pediatric patients 1 15 years of age of either sex, presenting with complaint of haematemesis were performed. The patients who were not fasting for 4 to 6 hours, or had undergone transjugular intrahepatic porto-systamic shunting or with history of haematemesis due to foreign body ingestion were excluded from the study. Doppler ultrasound of these patients was performed at Core Vision pro SSA 350-A Doppler machine (Toshiba, Japan). Our Standard imaging techniques with suspected or obvious portal vein thrombosis included scanning the patients in fasting state of $4-6$ hours, lying in supine or left lateral decubitus position. Portal vein was evaluated by either a subcostal approach with probe pointing postero-cephaled, or right intercostals approach with probe pointing medially. Doppler ultrasound signal abnormalities were looked for presence or absence of echogenic focus of thrombus in portal vein, velocity and direction of blood flow either towards or away from liver, pressure gradient, portal vein diameter as well as presence or absence of cavernous transformation was also looked for.

The data was stored and analyzed by using SPSS version 17 . The variables were presented as simple descriptive statistics mentioning mean and standard deviation for numerical data like age, velocity of blood flow in portal vein, diameter of portal vein and pressure gradient. Variables like portal vein thrombosis, acute portal vein thrombosis and chronic portal vein thrombosis were presented as frequency and percenttages.

\section{Results}

A total of 100 cases fulfilling the inclusion/exclusion criteria were enrolled in the study. Age distribution of the patients was done which shows $41 \%(\mathrm{n}=41)$ between $1-5$ years, $38 \%(n=38)$ between $6-10$ years and only $21 \%(\mathrm{n}=21)$ between $11-15$ years of age, mean $+\mathrm{SD}$ : $6.77 \pm 4.24$ years $($ Table 1$)$. Gender distribution of the patients shows $64 \%(n=64)$ were male and remaining $36 \%(\mathrm{n}=36)$ were females. Frequency of portal vein thrombosis in pediatric patients presenting with hematemesis reveals in $37 \%$ $(n=37)$ while $63 \%(n=63)$ had no findings of PVT.

Frequency of acute and chronic forms in patients positive for portal vein thrombosis was $40.54 \%$ ( $\mathrm{n}=$ $15)$ had acute and $59.46 \%(n=22)$ had chronic portal vein thrombosis.

Table 1: Age Distribution $(n=100)$.

\begin{tabular}{|c|c|c|}
\hline Age in Years & Number of Patients & Percentage \\
\hline 1 to 5 & 41 & 41 \\
\hline 6 to 10 & 38 & 38 \\
\hline 11 to 15 & 21 & 21 \\
\hline
\end{tabular}


Mean values of velocity of blood flow, pressure gradient and portal vein diameter in patients with acute and chronic portal vein thrombosis were recorded as $29.87 \pm 3.23,0.26 \pm 0.18$ and $15.76 \pm 2.30$ respectively in acute portal vein thrombosis while $12.27 \pm$ $5.10,0.14 \pm 0.03$ and $5.38 \pm 3.09$ were recorded in chronic portal vein thrombosis (Table 2).

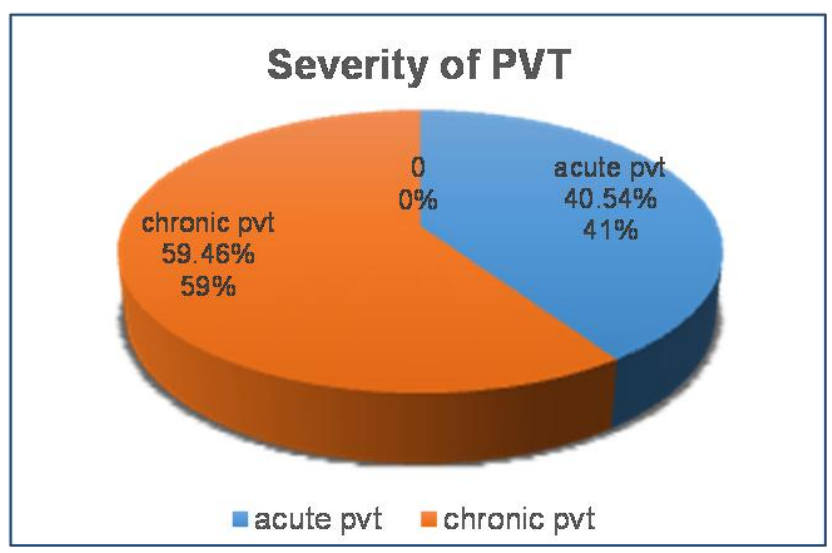

Fig. 1: Frequency of Acute and Chronic Forms in Patients Positive for Portal Vein Thrombosis $(n=37)$.

Table 2: Means Values of Portal Vein Diameter, Pressure Gradient and Velocity of Blood Flow in Patients with Acute and Chronic Portal Vein Thrombosis $(n=37)$.

\begin{tabular}{|l|c|c|c|}
\hline $\begin{array}{c}\text { Severity of } \\
\text { PVT }\end{array}$ & Velocity & Gradient & Diameter \\
\hline Acute & $29.87 \pm 3.23$ & $0.26 \pm 0.18$ & $15.76 \pm 2.30$ \\
\hline Chronic & $12.27 \pm 5.10$ & $0.14 \pm 0.03$ & $5.38 \pm 3.09$ \\
\hline
\end{tabular}

\section{Discussion}

Portal vein thrombosis is one of the most important causes of gastrointestinal bleeding in pediatric age group. Two third of the blood supply to liver is by portal vein. Portal hypertension occurs when portal vein pressure exceeds $10 \mathrm{mmHg} .{ }^{14,15}$ On color Doppler imaging the normal portal vein shows a continuous blood flow pattern, with a velocity ranging from 15 to $30 \mathrm{~cm} / \mathrm{s} .{ }^{16}$ In case of acute portal vein thrombosis the thrombus is an echoic and difficult to visualize. Chronic portal vein thrombosis is manifested as narrowed caliber of portal vein along with echogenic thrombus. Cavernous transformation at portahepatis is also an indicator of chronic portal vein thrombosis.
The incidence of portal hypertension (PHT) in the pediatric age group has fortunately decreased in the past decades, in contrast to adults, for whom the number of affected patients has dramatically increased. This is due of improved neonatal care and earlier diagnosis of conditions leading to portal hypertension. The mortality associated with bleeding is still approximately $20 \%$ at 6 weeks. ${ }^{17}$

Doppler imaging has a leading role in the evaluation of patients who have known or suspected portal hypertension as it can detect the hemodynamic changes in portal vein in case of portal hypertension. It provides information regarding the thrombosed veins via echo analysis, detecting presence of post-stenotic dilatation, flow defects and turbulence related to venous thrombosis. ${ }^{17,18}$

The limitation of Doppler ultrasound lies in interpatient variability and expertise of the given radiologist. ${ }^{19}$ In case of pediatric patients a radiologist having expertise in pediatric Doppler ultrasound can yield better and reliable results. But owing to the high sensitivity and specificity and its cost effectiveness Doppler imaging has a key role in early diagnosis of portal vein thrombosis. As early diagnosis and treatment has a huge impact on quality of life of these children.

The findings of the current study regarding frequency of portal vein thrombosis is in agreement with Schettino GC who recorded this frequency as $40 \%$ in children presenting with upper G.I bleed caused by esophageal varices. ${ }^{9}$ In the present study $51 \%$ children had chronic portal vein thrombosis and $49 \%$ had acute portal vein thrombosis.

A study by Adaletli I et al emphasized the importance of color Doppler ultrasound in evaluation of portal hypertension in children by comparing the results of grayscale and color Doppler ultrasound to that of multidetector computed tomography (MDCT) portography and concluded that Doppler ultrasound is superior to MDCT in identifying parenchymal and hemodynamic changes. ${ }^{20}$

\section{Conclusion}

The frequency of portal vein thrombosis in pediatric patients presenting with hematemesis is $37 \%$. Among these $40.54 \%$ were acute and $59.45 \%$ cases were of chronic portal vein thrombosis. Color Doppler ultrasound is a useful diagnostic modality being non-invasive and cost effective to evaluate the hemodynamic 
changes in portal vein thrombosis. As early detection will result in better outcome.

\section{References}

1. Bayraktar Y, Harmanci O. Etiology and consequences of thrombosis in abdominal vessels. World J Gastroenterol. 2006; 12: 1165-1174.

2. Wang JT, Zhao HY, Liu YL. Portal vein thrombosis. HepatobiliaryPancreat Dis Int. 2005; 4: 515-518.

3. Shah S, Butt J, Awan A. Profile of extrahepatic portal venous obstruction (EHPVO) in a tertiary care hospital in Pakistan. Pak J Med Sci. 2007; 23 (5): 677-80.

4. Machado M, Rosa A, Mota O, Cardoso D, Milhomem $\mathrm{P}$, Milhomem L et al . Ultrasonographic features of portal vein thrombosis. Radiol Bras, 2006; 39 (2): 151-155.

5. Ponziani FR, Zocco MA, Campanale C, Rinninella E, Tortara A, Di Maurizio L. Portal vein thrombosis: Insight into pathophysiology, diagnosis, and treatment. World J Gastroentrole. 2010; 16 (2): 143-55.

6. Sogaard KK, Astrup LB, Vilstrup H, Gronbaek H. Portal vein thrombosis; risk factors, clinical presentation and treatment. BMC Gastroenterology, 2007; 7: 34.

7. Wang JT, Zhao HY, Liu YL. Portal vein thrombosis. HepatobiliaryPancret Dis Int. 2005; 4: 515-18.

8. Ogren M, Bergqvist D, Bjorck M, Acosta S, Eriksson H, Sternby NH. Portal vein thrombosis: prevalence, patient characteristics and lifetime risk: a population study based on 23,796 consecutive autopsies. World J Gastroenterol. 2006; 12: 2115-19.

9. Schettino GC, Fagundus ED, Roquete ML, Ferreira AR, Penna FJ. Portal vein thrombosis in children and adolescent. J Pediatr (Rio J). 2006; 82: 171-78.

10. Quarrie R, Stawicki SP. OPUS 12 Scientist, 2008; 2 (3): 30-33.

11. Parikh S, Shah R, Kapoor P. Portal vein thrombosis. Am J Med. 2010; 123 (2): 111-9.

12. Deng MH, Liu B, Fang HP, Pan WD, Tang ZF, Deng P. Predictive value of $\mathrm{D}$-dimer for portal veinthrombsis after portal hypertension surgery in hepatitis B virus - related cirrhosis. World J Gastroenterol. 2007; 13 (48): 6588-92.

13. Sandhu GA, Rana MM, Bilal A, Qureshi FS, Abdullah R. Diversity of presentation in decompensated chronic liver disease due to HCV.A.P.M.C., 2011; 5 (1).

14. Carvalho AST, Mendes CMC. Hipertensãoporta: tratamento. In: Penna FJ, Mota JAC, Roquete MLV, Ottoni CMC, editores. Doenças do fígado e das viasbiliaresnainfância - Parte 2. Rio de Janeiro Medsi. 1999: p. 25994. [Links]

15. Pinto RB, Vieira SM, Silveira TR. Hipertensãoporta. In: Ferreira CT, Carvalho E, Silva LR. Gastroenterologia e hepatologiaempediatria. Diagnóstico e tratamento. Rio de Janeiro Medsi. 2003: p. 683-707.

14. Franchis R. Evolving consensus in portal hypertension. Report of the Baveno IV consensus workshop on methodology of diagnosis and therapy in portal hypertension. J Hepatol. 2005; 43: 167-76.

15. Ikeda M, Sekimoto M, Takiguchi S, Kubota M, Ikenaga M. High incidence of thrombosis of the portal venous system after laparoscopic splenectomy: a prospective study with contrast - enhanced CT scan. Ann Surg. 2005; 241: 208-16.

16. Silva RAP. Ultra-sonografia das doençashepáticas e biliaresnainfância. In Penna FJ, Mota JAC, Roquete MLV, Ottoni CMC, editores. Doenças do fígado e viasbiliaresnainfância - Parte 1. Rio de Janeiro Medsi. 1996: p. 45-88.

17. Franchis R. Evolving consensus in portal hypertension. Report of the Baveno IV consensus workshop on methodology of diagnosis and therapy in portal hypertension. J Hepatol. 2005; 43: 167-76.

18. Tessler FN, Gehring BJ, Gomes AS, Perrella RR. Diagnosis of portal vein thrombosis: value of color Doppler imaging. AJR Am J Roentgenol. 1991; 157: 293-6.

19. Wang J.T., Zhao H.Y., Liu Y.L. Portal vein thrombosis. HepatobiliaryPancreat Dis Int. 2005; 4: 515-518.

20. Adaletli I, Bariş S, Gülşen G, Kurugoglu S, Kantarci F, Mihmanli I, et al., Comparison of color doppler US and CT portography in evaluating portal hypertension in children. South Med J. 2012; 105 (1): 6-10. 